\title{
Mohamed Aït-Aarab, Mongo Beti, l'homme des ruptures
}

\section{Claudia Mansueto}

\section{(2) OpenEdition \\ 1 Journals}

\section{Edizione digitale}

URL: http://journals.openedition.org/studifrancesi/6128

DOI: 10.4000/studifrancesi.6128

ISSN: 2421-5856

\section{Editore}

Rosenberg \& Sellier

\section{Edizione cartacea}

Data di pubblicazione: 1 mai 2011

Paginazione: 224

ISSN: 0039-2944

\section{Notizia bibliografica digitale}

Claudia Mansueto, «Mohamed Aït-Aarab, Mongo Beti, I'homme des ruptures», Studi Francesi [Online], 163 (LV | I) | 2011, online dal 30 novembre 2015, consultato il 08 janvier 2021. URL: http:// journals.openedition.org/studifrancesi/6128; DOI: https://doi.org/10.4000/studifrancesi.6128

Questo documento è stato generato automaticamente il 8 janvier 2021.

\section{(c) (i) $\ominus$}

Studi Francesi è distribuita con Licenza Creative Commons Attribuzione - Non commerciale - Non opere derivate 4.0 Internazionale. 


\title{
Mohamed Aït-Aarab, Mongo Beti, l'homme des ruptures
}

\author{
Claudia Mansueto
}

\section{NOTIZIA}

MOHAMED AÏT AARAB, Mongo Beti, l'homme des ruptures, «Essays in French: Literature and Culture», n. 46, 2009, pp. 249-264.

1 Condannato ad un ingiustificato oblio, Mongo Beti è sicuramente uno degli intellettuali africani più rappresentativi del panorama letterario contemporaneo. Sempre al fianco dei più deboli, Beti ha lottato tutta la vita contro le ingiustizie e le discriminazioni, perché il suo obiettivo primario era quello di contribuire alla costruzione di una società equa ed indipendente dalla «monstruosité» coloniale (p. 251). Aït-Aarab si sofferma soprattutto sull'atteggiamento contestatario dell'intellettuale francofono: homme en colère et éngagé come Sartre, Beti considera la letteratura lo strumento ideale per diffondere una realistica "vision sociologique» (p. 251) su un Paese come il Cameroun che ha conosciuto prima la tirannia straniera e poi i disastrosi effetti di una politica nazionalista corrotta. L'originalità di Beti, come evidenzia il critico, risiede nella sua capacità di essere contemporaneamente un intellettuale che ama teorizzare e un attivo interventista, impegnato nella risoluzione dei problemi più urgenti che affliggono il suo Paese. Ed è proprio la coesistenza di queste due anime, non facilmente conciliabili, che fa dello scrittore camerunense, autore di best-sellers come Remember Ruben (1974) e L'histoire du fou (1994), un homme de ruptures capace di creare nel tessuto sociale e letterario quelle discontinuità ideologiche necessarie per favorire il dialogo e la crescita. Aït-Aarab, citando Philippe Bisseck, ricorda come Beti fosse un uomo privo di risentimento anche nei confronti dei suoi stessi nemici: la costante mano tesa verso $i$ suoi più ostinati detrattori è la prova tangibile dell'indiscussa bontà d'animo di questo moderno Don Quijote, sempre pronto a lottare contro i mulini a vento dell'immobilismo culturale e civile. Nel corso della sua carriera, Beti, pseudonimo di Alexandre Biyidi Awala, ha utilizzato le sue battaglie come un esempio per esortare tutto il popolo 
africano all'unione e alla rivendicazione dei diritti più elementari. Seguace di Nyobé, Beti diffida della cooperazione francese per garantire un duraturo sviluppo del continente africano e proprio il persistere dell'invadenza occidentale è da lui definito come un «avatar honteux du colonialisme de papa et un centralisme sans aucun rapport avec sa tradition et les exigences de son progrès» (p. 262).

2 L'articolo di Aït-Aarab ha il merito di riportare l'attenzione su un grande scrittore, originale e coerente, che ha lottato per tutta la vita contro la rassegnazione di un popolo devastato dalla tirannia colonizzatrice sempre vigliaccamente restia «à regarder en face son passé, à avouer ses fautes» (p. 264). 